
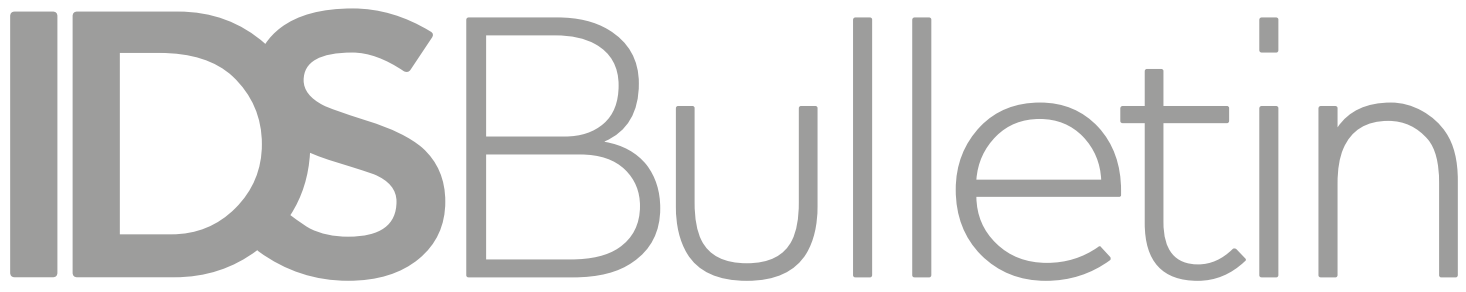

Transforming

Development Knouledge

Volume 50 | Number 2 | July 2019

\title{
THE POLITICAL \\ ECONOMY OF \\ FOOD
}

Editors Jody Harris, Molly Anderson, Chantal Clément and Nicholas Nisbett

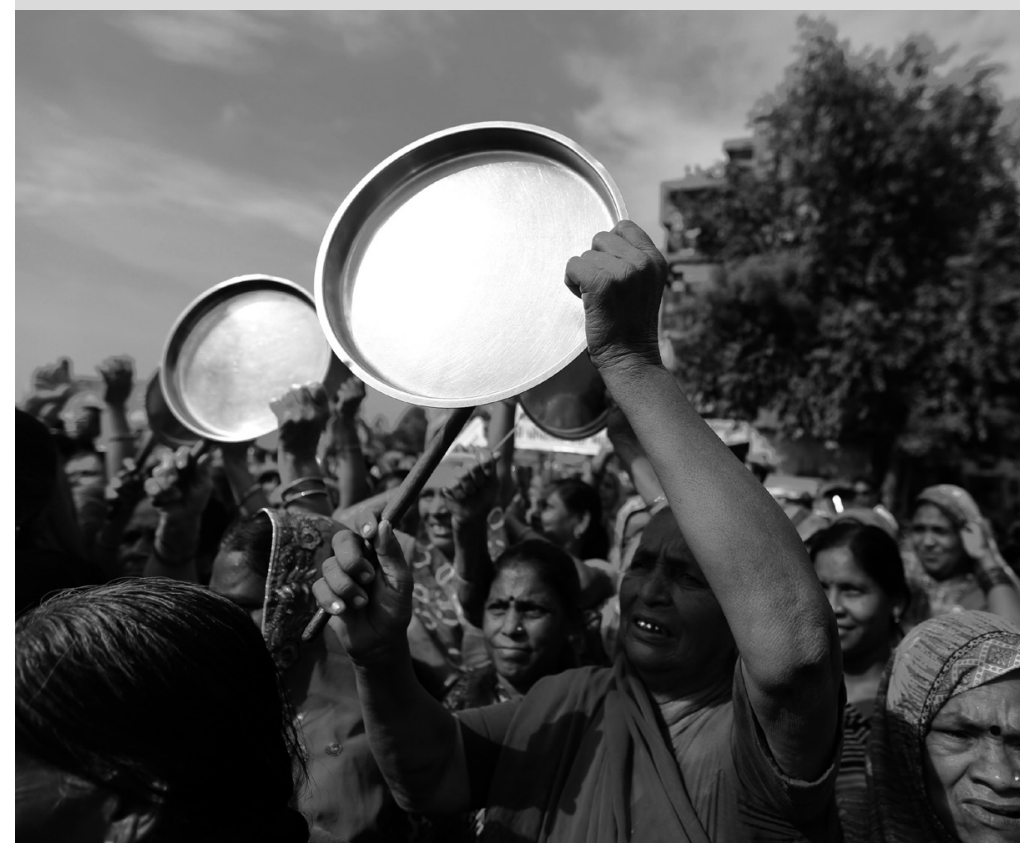


Notes on Contributors

Introduction: Valuing Different Perspectives on Power in the Food System

Molly Anderson, Nicholas Nisbett, Chantal Clément and Jody Harris

The Political Economy Approach to Food Systems Reform

Olivier De Schutter

Reflections on IPES-Food: Can Power Analysis Change the World?

Desmond McNeill

Envisioning New Horizons for the Political Economy of Sustainable Food Systems Jessica Duncan, Charles Z. Levkoe and Ana Moragues-Faus

Evidence-Based Policymaking in the Food-Health Nexus

Cecilia Rocha and Jody Harris

Purchasing and Protesting: Power from Below in the Global Food Crisis

Naomi Hossain and Patta Scott-Villiers

\section{Agroecology and Food Sovereignty}

Steve Gliessman, Harriet Friedmann and Philip H. Howard

Building a Sustainable Food City: A Collective Approach

Emily O'Brien and Nicholas Nisbett

Power in the Zambian Nutrition Policy Process

Jody Harris

Transforming Food Systems: The Potential of Engaged Political Economy

Molly Anderson and Melissa Leach

Glossary 


\title{
Agroecology and Food Sovereignty ${ }^{+}$
}

\author{
Steve Gliessman, ${ }^{1}$ Harriet Friedmann ${ }^{2}$ and \\ Philip H. Howard ${ }^{3}$
}

\begin{abstract}
We propose that agroecology provides a framework for understanding 'levels' for the transition to sustainable food systems. If we agree that agroecology includes social and political dimensions of governing territorial food systems, then it must be linked to movements for food sovereignty. However, the concentration of power in food and farming systems locks in industrial logic, posing immense barriers to agroecological and social transition. This creates a tension between efforts at convergence of food system innovations from below, versus co-optation of grass-roots language and practices by private and public actors who are committed not to changing the logic of industrial agriculture, but instead to reducing its harm. We suggest agroecological and food sovereignty movements consciously embrace this tension as a dance of creativity and appropriation. If this dance can be made generative rather than deadly, it can open pathways for transition to new ways of seeing, experiencing, and getting food.
\end{abstract}

Keywords: agroecology, buen vivir, transition, sustainability, food sovereignty, power, social movements.

\section{Introduction}

What would societies and landscapes look like if food systems were designed to promote a good life - what many in Latin America call buen vivir? To ask this question is to appeal to common sense - what else should our food system activities be for? It is also to reveal how far from this goal are our present ways of growing and eating, and all the steps in between. It means asking why and how values of wellbeing are marginalised by goals of efficiency (to maximise what?) and profit (whose?). Movements for agroecology and food sovereignty in distinct ways undertake to move the growing, marketing, preparing, and sharing of food in the direction of health for land and people. They connect food, land, and cultures in specific places, and create networks to share and coordinate activities across these places.

Agroecology and the food sovereignty movement have deep affinities - despite a rocky history of conflicts within and between social movements and non-governmental organisations (NGOs). From its 
modern beginnings in Mexico in the mid-1970s (Gliessman 2016a), to many of the recent agroecology movements around the world (e.g. Campesino à Campesino, La Via Campesina, Slow Food), people have been using agroecology to build strong local food systems rooted in local knowledge, culture, and food production and consumption practices. With its holistic, ecosystem focus, agroecology has supported research, practices, and social change processes needed for moving the entire food system towards sustainability, from the seed and the soil to the table, despite the barriers that keep all parts of the food system locked in to the centralised, industrial model of food production and consumption (IPES-Food and Frison 2016). The science and practice of agroecology are more effective as a tool for change when implemented within a framework of food sovereignty, as this requires engagement with power in many parts of the industrial food system. And since its alignment with agroecology (Gliessman 2015), the food sovereignty movement has deepened its focus on territorial and cultural integrity to include collaboration between farmers and scientists to enhance farming in tune with ecosystems.

\section{What is agroecology?}

Agroecology is the application of the science of ecology (the science of how nature works) to the study, design, and management of sustainable food systems; the integration of the diverse knowledge systems generated by food system practitioners to serve social movements that are promoting the transition to just and sovereign food systems (FAO 2018; Gliessman 2015). In other words, agroecology is understood in this chapter as a science, a practice, and as a social movement within the food sovereignty movement, in line with the action-oriented description of agroecology agreed upon at the Nyéléni convention held in 2015 (International Forum for Agroecology 2015). Diversified agroecological systems, as defined by the International Panel of Experts on Sustainable Food Systems and Frison (2016; IPES-Food 2018), encompass wideranging practices with a clear direction of travel: diversifying farms and farming landscapes, replacing chemical inputs with ecologically-based materials and processes, reducing waste by closing material cycles, reducing fossil-fuel energy use by maximising biomass accumulation and internalising energy flows, optimising biodiversity, and stimulating interactions between different species, as part of holistic strategies to build long-term fertility, healthy agroecosystems, and secure and just livelihoods. The ecosystem concept, with all of its flows, cycles, and reciprocal feedbacks and interactions, is key to how diversified agroecosystems operate.

\section{How does agroecology promote transition to sustainability?}

We adopt Gliessman's (2015, 2016b) framework for classifying 'levels' of food system change. The first three levels describe the steps farmers can take on their farms to convert from industrial or conventional agroecosystems. Two additional levels go beyond the farm to the broader food system and the societies in which they are embedded, and point towards food sovereignty for everyone involved. Although the 
five levels taken together can appear to be a stepwise process, in reality, multiple entry points and interacting processes can (and must) work in concert with agroecology to ensure food system transformation (IPES-Food 2018):

\section{Level 1: Increase the efficiency of industrial/conventional practices in order to reduce the use and consumption of costly, scarce, or environmentally damaging inputs.}

The primary goal of change at this level is to use industrial inputs more efficiently so that fewer inputs will be needed and the negative impacts of their use will also be reduced. Most conventional agricultural research has taken place at this level, through which considerable modern agricultural technologies, inputs, and practices have been developed. This research has helped farmers maintain or increase production through such practices as improved seeds, optimum planting density, more efficient pesticide and fertiliser application, and more precise use of water. So-called precision agriculture is a recent focus of research at Level 1. Although this kind of research has reduced some of the negative impacts of industrial agriculture, it does not help break its dependence on external material inputs and monoculture practices. Breaking away from this dependence is a key goal of food sovereignty, while retaining the logic of industrial agriculture is at the heart of such practices as sustainable intensification.

\section{Level 2: Substitute alternative practices for industrial/conventional inputs and practices.}

The goal of this level of transition is to replace external input-intensive and environmentally degrading products and practices with those that are more renewable, based on natural products, and more environmentally sound. Organic farming certification, as currently practised, is a good example of this approach. For instance, some farmers use nitrogen-fixing cover crops to replace synthetic nitrogen fertilisers, some use rotations and companion planting for natural controls of pests and diseases instead of industrial pesticides, and others use organic composts for fertility and soil organic matter management. However, at this level, the basic agroecosystem is not usually altered from its more simplified form; hence, many of the same problems that occur in industrial systems also occur in those with input substitution.

Level 3: Redesign the agroecosystem so that it functions on the basis of a new set of ecological processes.

At this level, fundamental changes in overall system design eliminate the root causes of many of the problems that continue to persist at Levels 1 and 2. The focus is on prevention of problems before they occur, rather than trying to control them after they happen. At this level, research on whole-system conversions provides an understanding of key yield-limiting factors. Agroecosystem structure and function is better understood, and appropriate changes in design can be implemented. Problems are recognised, and adjustments made in internal site- and time-specific design and management approaches, 
instead of solely by the applications of external inputs. A good example is the reintroduction of diversity in farm structure and management through such actions as ecologically-based rotations, multiple cropping, permaculture, agroforestry, and the integration of animals with crops. When diversification is a key focus in the transition, elements of food sovereignty begin to appear both in independence from outside purchased inputs, as well as in an increase in products and services that a more diverse agroecosystem can provide.

These first three levels were the focus of agroecology during its early development as a science, with a primary focus on farm-based changes (Gliessman 1997). But as the development of alternative markets (Gliessman 2007) and the food sovereignty movement aligned with agroecology (Gliessman 2015), two more levels have been added. Farmers began to build networks with other farmers, and consumers began to seek more direct relationships with the producers of their food. What was a more technical farm movement became a more social food movement.

Level 4: Re-establish a more direct connection between those who grow our food and those who consume it.

Food system transformation occurs within a cultural and economic context. At a local level, this means that those who eat must value food that is locally grown and processed, and support with their food purchases the farmers who are attempting to move through Levels 1-3. This support becomes a kind of 'food citizenship' and can be seen as a force for food system change. Communities of growers and eaters can form direct food networks in places across the world to build new and sustainable food cultures and economies. Food once again must be grounded in direct relationships. An important example is the current food 're-localisation' movement, with its growing networks of farmers' markets, community-supported agriculture schemes, consumer cooperatives, and other marketing arrangements that shorten the food chain. Similar connections can be made to shorten food chains over long distances, such as fairly traded commodities like coffee and cacao (case study 2 in IPES-Food 2018). Sovereignty can begin to appear for the farmer, the eater, and everyone in between as direct relationships turn into stable food networks.

Level 5: On the foundation created by the sustainable farm-scale agroecosystems achieved at Level 3 , and the new relationships of sustainability of Level 4, build a new global food system, based on equity, participation, democracy, and justice, that goes beyond sustainability to help restore and protect earth's life support systems on which we all depend. By thinking beyond Levels 1-4, Level 5 involves change that is global in scope and reaches beyond the food system to the nature of human culture, civilisation, progress, and development. Leaving the change process to the market, as it might appear if we only change market systems at Level 4, is not enough. The depth of change is more than mere conversion or transition, and enters into the realm of full reform or transformation in how we live and our understanding of what a good 
life is (see buen vivir below). Within Level 5 thinking and action, there are ways to build upon farm-scale and farmer-driven change processes to a full re-thinking, shifts in values, and changes in the spirit and the heart of how we all relate to each other and to the earth that supports us. Basic beliefs, values, and ethical systems change.

The expanding awareness of the centrality of farming and food to societies as a whole extends to other facets of environmental and social relationships. This is a paradigm shift focused on how agriculture and food can help reduce our ecological footprint, even make food and farming regenerative of ecosystems, including a shift from obsession with growth to embracing what it really means to live sustainably. The important role that food systems can and must play in mitigating and adapting to climate change as a global issue is one example of the value of Level 5 thinking; another is enhancement of cultivated and wild biological diversity (Perfecto, Vandermeer and Wright 2009); another is by contributing to the ecosystem services normally provided by nature that keep our air, water, and soil systems healthy. The growing food justice movement, where everyone in the food system enjoys the benefits of equity, justice, security, and sustainability, is yet another. All of these elements together contribute to the development of food sovereignty.

What will our food system with sovereignty look like when Level 5 thinking and action guides the changes that need to take place? What are the incentives needed to stimulate these changes? Can this thinking bring about needed changes in policy, support systems, funding, and choice? Can Level 5 thinking determine steps at other levels, depending on where the farmer or the food system is at the moment? Level 5 change also requires confronting power in the globalised food system in which pursuit of profit locks in the opposite of agroecology and food sovereignty - concentration, simplification, and exclusion. This puts the need to shift from a regime subsidising industrial inputs and practices to one that places agroecology and food sovereignty front and centre.

\section{What is food sovereignty?}

Food sovereignty is an aspiration widely shared by movements in cities and countrysides, in the North and in the South. It aspires to justice, autonomy, and living in balance with the rest of nature (Friedmann 2016). Growing food is how we work with the land and other beings, and how we nourish human bodies and human cultures. Growing food and feeding bodies are both fundamental to the ways societies work, yet are marginal to dominant theories and policies which have long privileged industry - and now industrial agriculture. Food sovereignty is one of the ways to move the food system back to the centre of consciousness and action.

Food sovereignty challenges the claim by corporations to 'feed the world'. It has been suggested that small farmers produce more than 50 per cent globally and 70 per cent in the global South of all the diverse plants and animals people actually eat (Samberg et al. 2016). 
This is especially the case when including production that is not marketed through documented channels, is directly exchanged, or is consumed locally. Although definitions of 'small farms' vary, it is important to counteract the false impression from global statistics where the only 'foods' counted are the crops that enter into international trade. By contrast, the handful of grains and oilseeds traded by corporations largely feed animals and vehicles instead of people, and when they feed people it is processed foods of dubious nutrition (De Schutter et al. 2015). Yet maize, soy, palm oil, and wheat are the main crops included in measures of food insecurity, and sudden increases in their prices are what is meant by food crises. The spread of these crops as monocultures pushes out small, diverse farms and makes it difficult for many people to obtain the diverse fruits, vegetables, and animal products needed for nutritious diets. Food sovereignty poses the goal of connecting growers and eaters with each other and with the earthly relations that sustain us all. Reconnection is crucial to evolving and emerging cuisines that in turn support living cultures. Crucial to reconnection is recognition of the fact that being a farmer is an important occupation, one that carries with it knowledge crucial to sustaining ecosystems and cultures, and that farmers must be supported to guide the evolution of the diverse crops they plant, tend, and harvest.

The idea of food sovereignty has evolved since it was publicised over two decades ago by La Via Campesina, a transnational network of farmer-led organisations. The most widely used definition of food sovereignty is from the 'Declaration of Nyéléni', ${ }^{4}$ by delegates from more than 80 countries at a forum in Mali:

Food sovereignty is the right of peoples to healthy and culturally appropriate food produced through ecologically sound and sustainable methods, and their right to define their own food and agriculture systems. It puts those who produce, distribute and consume food at the heart of food systems and policies rather than the demands of markets and corporations (Nyéléni 2007).

This definition includes a goal of renewing food systems for future generations, and thus connected it to agroecology even before aligning the two formally in 2015. It also includes a statement of what locks in the dominant food system to relations of power and exclusion:

[Food sovereignty] defends the interests and inclusion of the next generation. It offers a strategy to resist and dismantle the current corporate trade and food regime, and directions for food, farming, pastoral and fisheries systems determined by local producers (ibid.).

The Nyéléni declaration continues in language that leaves open what sovereignty looks like for different places, and how to balance prefigurative with oppositional politics; that is, the creation of new ways of organising food systems with resistance to powerful interests pursuing the dominant system: 
Food sovereignty prioritises local and national economies and markets and empowers peasant and family farmer-driven agriculture, artisanal fishing, pastoralist-led grazing, and food production, distribution, and consumption based on environmental, social, and economic sustainability (Hoey and Sponseller 2018).

\section{How are people trying to create food sovereignty?}

Strategies to create social autonomy and ecological integrity are necessarily diverse because of specific natural and cultural contexts. The diversity of strategies mirrors and anticipates the goal of a food-sovereign world whose unity is based on a diversity of places. Autonomy and cooperation build on existing conditions in each territory, and people in those territories seek ways to mutually support strategies and initiatives. One model is the 'water protectors' who connect with the food sovereignty movement, and show how governance by self-organising communities might mirror the hydrosphere - each stream is unique and flows into larger bodies of water, which flow into the oceans, move as vapour into the air, and fall as rain.

Within this diversity, it is possible to distinguish two pathways towards a shared goal, depending on the starting point. One pathway is for farmers and territories made marginal by the dominant system. They have knowledge of their places, and how to grow, share, trade, and use wastes in their ecosystems. However, often these ecosystems and social relations have been degraded and pushed to the margins by expanding industrial and other land uses; land, social relations, and knowledge have been lost as communities have been disorganised and transmission across generations has been disrupted by migration, land concentration, adoption of chemical methods, and dependence on buying and selling in far-flung markets dominated by powerful corporations. These farmers and territories need support to move along a distinct pathway towards food sovereignty, which includes reconstituting territorial markets, renewing rights to land and water, and protecting themselves against outside forces that undermine them (IPES-Food and Frison 2016).

This means public policies to enhance farmer knowledge and control over seeds and protecting territorial markets, which are where most food is channelled and where most small farmers meet customers in ways that support the link with cultural cuisines (Civil Society Mechanism 2016). Most of all, it means public policies to secure tenure for small farmers; it means finding a balance between protecting customary land from conversion into saleable units through formal titles (Ho and Spoor 2006) - and at the same time protecting individual rights especially for women and youth (Prindex 2018; ILC LEMU 2018). The challenge of protecting land and supporting small farmers is that current institutions and policies promote capitalist monopolies, overproduction, and monocultures, with all their ecological harms and exploitative labour practices.

The other pathway to food sovereignty is for industrial farmers who are currently locked into debt, chemical dependency, and contracts 
to agrofood corporations, all requiring that they produce single crops, and ever narrowly specified crop varieties. Rural communities have lost people, social relations and institutions, knowledge, and health of land and water. The extent and forms of this loss depend on how long farmers have been locked in, what kinds of subsidy and other policies are in place, and what kinds of contracts with agrofood corporations have shaped their farming practices. Farms became bigger by consolidating land from neighbours, and the mix of activities that characterised rural villages and towns disappeared - education, health, even access to goods for personal life or to continue to produce crops and livestock, could be had only at a distance, if at all, and only for cash. These farmers and territories need to begin to close broken cycles. For instance, shifting to Level 2 (see above), US farmers have begun to use cover crops to replace soil nitrogen and renew soil ecologically, thus withdrawing some of their dependence on purchased inputs, bank debt, and technological advice to continue on the treadmill of chemicals and degradation (Blesh and Wolf 2014).

Both need a different type of agricultural science than the one that agrofood and chemical corporations, and for the most part also governments, have promoted. The agrochemical industry, which now calls itself part of the 'Life Sciences Sector', used to be called the pesticide industry. The common use by critics of the term 'agrotoxins' rather than 'agrochemicals' suggests the war of words in which food sovereignty is engaged. The agronomy (and its measures of single-crop yields) are sponsored by both agrochemical corporations and most public sector research. It leads to monocultures, whose dependency on chemical inputs and whose need to dispose of wastes is intrinsically linear. In place of linear systems which lead to depletion somewhere outside the territory and to dumping of wastes also somewhere outside, farmers need the science of agroecology, which supports a return to cycles in which everything is used and re-used. For example, instead of separating animals and crops, animals large and small can help to replenish soil nutrients, to control pests, and more, while parts of crops or land not usable by humans can feed them (De Schutter 2009). This requires a shift of public research towards ecological science, and for top-down advice towards collaboration between formal science and the practical place-based knowledge of farmers (IAASTD 2009).

At the same time, since most of the world's people now live in cities, food sovereignty is about reconnecting all participants in the food system to the places they live (Friedmann 2011). We can only know how to do this, and how to connect well across places by experimenting in the shadows of the dominant system. One of the promising approaches for use of urban rural land is the concept and practice of commoning. Eight principles for creating successful commons have emerged from the comprehensive comparison of cases from across the world, past and present by Nobel laureate Elinor Ostrom and her colleagues (Walljasper 2011). These begin with defining clear group/community boundaries and matching rules governing use of common goods to local needs and conditions; they then focus on what we now call governance - 
participation, autonomy, community monitoring and enforcement, and dispute resolution; most important, they envision a different world of territorial politics consisting of nested tiers from the lowest level up to the entire interconnected system. At the same time, in settler regions such as North and South America, commons were introduced as part of colonial appropriation of indigenous lands; therefore, its relation to cosmovisions expressing deeper and wider ways of living is to be explored, possibly in relation to buen vivir.

Numerous grass-roots experiments anticipate the possibility for food sovereignty. The oldest are organics and fair trade, two certifications that resulted from efforts to reduce the negative impacts of highly concentrated, industrial food systems, which are now largely captured by the dominant system (Jaffee and Howard 2010). Organics invented modern certifications, which have now morphed into traceability along extended corporate supply chains. Fair trade created links between responsible consumers and farmers, now subject to corporate control and greenwashing (Friedmann 2005). Closing broken connections between urban and rural places is undertaken by a wide array of practices, including urban agriculture, community-supported agriculture, farm and food cooperatives, urban or regional food policy councils, recently reaching global politics through networks of cities under the Milan Urban Food Policy Pact, and important initiatives to regulate corporations and support small farmers through the Civil Society Mechanism of the Committee on Food Security (McKeon 2015).

Yet corporations become ever more adept at co-opting what works for them in alternative food systems, especially as public awareness has grown about health and environmental costs of industrial food and farming (Friedmann 2005). They adapted to the growing success of organic by changing standards from a focus on building soil health into a list of prohibited substances; that is, an 'input substitution' model. This means that some toxic substances were reduced; but large-scale, simplified single-crop operations remained in place (Rosset and Altieri 1997). They adapted to the increasing success of fair trade by, for instance, encouraging the leading certifier in the US to allow this label on the products of large coffee and cacao plantations, although it had previously been limited to small-scale farms for these crops (Jaffee and Howard 2016). Organic food sales are now dominated by global food processors such as General Mills and Danone, and fair-trade sales are dominated by global processors and retailers such as JAB and Starbucks. The same can be said of no-till farming, now mainly for GM crops but anticipated by the critique of chemical-intensive agriculture by The Land Institute (Crews et al. 2016).

\section{What is preventing a transition to food sovereignty and diversified agroecological systems?}

Public debates over 'solutions' to the problems that confront food and agricultural systems are frequently steered in directions that do not lead to fundamental changes. Such 'managerial' approaches often fail 
to examine underlying drivers, and therefore limit the possibilities for actions that can be taken (Hornborg 2011; Friedmann 2017). The problems themselves are typically framed in terms that lead logically to continuing on current paths, albeit with increased production, less waste or improved waste disposal, and/or the wider application of new technologies. Lack of food, for example, is defined not as a problem of unequal distribution of calories, or of the focus on feed crops rather than the mix of foods humans need, but instead as a problem of insufficient production. The focus on increasing production of what is already produced requires the application of technologies that further industrialise and centralise food systems - the same systems that fail to effectively distribute a current level of production that could easily provide enough calories for everyone (Chappell 2017). It means continuing to produce the wrong mix of crops to nourish the world's human population, and threatens to deepen the problems of land degradation (despite more precise applications of nitrogen or pesticide) and of resistance by pests and weeds that compete against crops. The power of corporations locking in this trajectory towards improvements rather than transformation is now deeply embedded in the debt cycle that locks in farmers and governments to existing practices (Streeck 2017).

This is not an accident, but a result of concentrating power in the hands of fewer and fewer people and corporations, who then actively oppose efforts to reduce their influence. It includes disparaging and sabotaging promising alternatives, such as food sovereignty and agroecology, with rationales that deflect attention away from the disproportionate benefits elites receive from unequal power relations (Freudenburg and Alario 2007). The concentration of power reinforces a number of 'lock-ins' that lead to vicious cycles of debt, chemical dependence, and unequal diets for rich and poor consumers, further reducing the possibilities for moving towards more sustainable alternatives (IPES-Food and Frison 2016).

Power can be defined broadly as 'the capacity of some persons to produce intended and foreseen effects on others' (Wrong 1995: 2). Concentrated power enables a very small number of people to shape and re-shape society in ways that strengthen their dominance and catalyse increasing inequality. They are aided by institutions such as corporations, governments, media, foundations, thinktanks and education systems, and elite individuals may move easily between these different types of organisations (Domhoff 2014). Importantly, this influence is frequently hidden, exercised indirectly, and even 'naturalised' so that the majority of people take it for granted and do not question it (Gramsci 1971; Gibson-Graham 2006; Streeck 2017).

Power can be very difficult to measure, but Nitzan and Bichler's framework of Capital as Power (2009), suggests that it can be quantified when viewed from the perspective of capitalists themselves. For publicly traded corporations, their market capitalisation is technically the current share price multiplied by the number of shares outstanding. 
However, market capitalisation may also be viewed as capitalists' consensus expectations that people will continue to acquiesce to a particular firm's power in the future, after discounting for potential risks (ibid.). By this metric, power in dominant food and agricultural industries (as well as other industries) has increased dramatically and continues to rise (Howard 2016). The top 25 firms in the world by market capitalisation, for example, include the retailer Walmart, the food processor Nestlé, and the beverage firm Coca-Cola - all three have more than doubled their market capitalisation in the last 25 years, and most other leading firms have achieved similar growth rates.

Executives in these firms must seek to gain additional power relative to other dominant firms, or they will lose shareholders (primarily the world's wealthiest individuals) and become vulnerable to takeover. This system fuels consolidation, particularly when firms are unable to achieve sufficient growth within their own organisational boundaries. Instead, they must bolt on increased power and market share by buying out other firms. Anti-trust laws enacted in many nations in the early 1900s once slowed this process (Lynn 2009), but by the end of that century such regulations had been drastically reshaped to allow very large buyouts. In 2016, for example, the world's leading beer firm, Anheuser-Busch InBev, acquired its second largest competitor, SABMiller, for US\$103bn, after making only minor divestments to obtain approval from regulators in the US, the EU, and China - this resulted in control of approximately 28 per cent of global beer sales.

Interestingly, mergers and acquisitions frequently result in a market capitalisation higher than the sum of the separate firms before their combination. Such a valuation does not make sense if this only reflects the material and human resources embodied in these firms, and instead suggests an expectation of increased influence over society (Nitzan 1998). Improvements in efficiency and/or rates of innovation are typically promised to result from increasing economic concentration, but abundant empirical evidence suggests that it usually has the opposite effect (Adams and Brock 2004). Firms accumulate their power through strategic sabotage (Veblen 1923), which undermines the autonomy of others, not only in the economic realm, but by reducing innovation and efficiency throughout society (Bichler and Nitzan 2017).

Even alternatives that work very hard to avoid the dominant system are therefore inescapably influenced by it; for instance, facing stronger regulatory barriers and receiving far fewer subsidies (or none) in comparison to the largest food and agricultural firms. This process creates a vicious cycle, further increasing the political power of the largest firms, and strengthening their ability to re-shape subsidies in their favour. The governments of Brazil and China, for example, financed low-cost loans that enabled dominant meat processors headquartered in these countries to buy out even larger competitors on other continents. These firms, JBS and WH Group respectively, have become powerful lobbyists in the US, the EU, and Australia. 
Subsidiaries of both firms are eligible for bailouts from the US government resulting from its recent trade war with China, even though the WH Group is itself headquartered in China (Meyer 2018).

Many subsidies are more indirect or hidden, such as governmentfunded infrastructure for industrial-scale storage and transportation, or regulatory environments that allow the real costs of industrial food systems to be shifted to everyone else (Carolan 2018). The expansion of soy production in Brazil, for example, results from clearing biodiverse ecosystems, including the Amazon rainforest and the neighbouring Cerrado savanna. Government-constructed roads and ports have accelerated this deforestation, and the majority of soybeans are exported as livestock feed to other continents (where environmental regulations are stricter, and production costs are higher), particularly East Asia and Europe (Oliveira and Hecht 2016).

Regulatory barriers that hinder food sovereignty and increase the difficulty of using agroecological practices are also increasing. The global seed industry, for instance, has over the past few years become dominated by just four firms (Bayer, Corteva, ChemChina/Syngenta, and BASF), which resulted from the combination of what were 30 separate agrochemical firms just a few decades ago. Concurrently, the ability to exchange seeds freely has become more restricted via laws that threaten farmers with fines and jail terms for non-compliance with protection for patented seeds (Howard 2015; GRAIN 2015). Similarly, new food safety regulations designed for large corporations have put small retailers and local farmer cooperatives at risk, and narrowed retail outlets for small-scale and agroecological producers (DeLind and Howard 2008; GRAIN 2011).

More broadly, powerful institutions have reshaped society to encourage the attrition of resources, skills, and knowledge needed for self-reliance - this process erodes the foundations needed to create successful alternatives. One example is 'deskilling', a term that applies not just to labour, but to household food production, preparation, and consumption (Jaffe and Gertler 2006). Educational institutions that are heavily funded by food processors, for example, have steered people towards eating more highly processed foods, such as canned soups, instead of fresh foods (ibid.). These actions have not gone unopposed, however, and initiatives to encourage 'reskilling', such as gardening, seed saving, homebrewing, and canning, are on the rise (Barnes 2014). There has also been some success in shifting educational purchases towards healthy foods sourced from local producers, certified, for instance, by the 'Food for Life' certification by the British Soil Association (Stahlbrand 2016; Morgan and Morley 2014).

In the face of persistence by those with power to protect the status quo, if resistance to particular practices becomes high enough, or alternatives become successful enough, they must be willing to adapt, indeed to take advantage of selected innovations from below to improve their 
performance. This adaptation is focused in directions that enable their power differentials to be maintained or increased, even if it involves ameliorating some of the collateral damage inflicted upon society or ecosystems with previous practices. Co-optation is therefore a two-way process in which alternatives become incorporated into the mainstream, thus partially achieving social movement goals, but at the expense of elements that are most threatening to existing power relations (Jaffee and Howard 2010), and those most promising for a transition to agroecology and food sovereignty.

How can the food sovereignty movement confront the power of the industrial food system so that sovereignty can be achieved? As for organic and fair trade, agroecological innovations will continue to face pressures of co-optation. Powerful institutions seeking to protect their profits and power are working to reduce agroecology to merely a set of tools for Level 1 or Level 2 changes. They are narrowing its scope to 'sustainable intensification' or 'climate-smart agriculture', and attempting to make it compatible with technologies (e.g. genetic engineering) that are monopolised by dominant corporations (Holt-Giménez and Altieri 2016). Seed/agrochemical giants, for instance, have been spending billions of dollars to acquire biological control firms since 2012, such as Bayer's purchase of AgraQuest and Prophyta, BASF's purchase of Becker Underwood, and ChemChina/ Syngenta's purchase of Pasteuria Bioscience. The trend of increasing power also tends to elicit more resistance, however, as previously hidden socioecological impacts become more visible and limits to public acquiescence are reached (Bichler and Nitzan 2012).

\section{Conclusion}

Efforts to achieve food sovereignty and diversified agroecological systems have the potential to dismantle concentrations of power, particularly if they pay sufficient attention to the means used to achieve their goals. This will require fostering decentralisation, horizontal proliferation, cooperation, and transparency. To develop mutually reinforcing 'virtuous cycles', where one part of the food system connects directly with others, will require embodying our ideals as much as possible. Actions in this direction include both everyday practices of good growing, good markets, and good eating, and shifts in laws and regulations away from those made to support industrial agriculture and lock in corporate control. It means reconnecting all the elements of growing and eating that have been broken apart and turned into profit opportunities to build corporate control over ever more complex supply chains (Cronon 1991).

Most of all, this transition will require deepening links between agroecological science and practice, and the social movements working for food sovereignty. Case studies of transition towards agroecology in the latest report from IPES-Food (2018) provide examples that include the goal of food sovereignty. Linking agroecology and food sovereignty as social movements is key to confronting the power of the industrial food system. This requires analysis of power, both of corporations 
and states sustaining the present dangerous trajectory of 'sustainable intensification' (Level 1), and of social movements living and working towards a new relation with nature, including our own better selves. How humans get our food is at the heart of what is wrong and what is right about how we relate to each other, to the ecosystems we inhabit, and to the earth. Other struggles for just and loving relationships (e.g. women's empowerment, renewed social and economic roles for youth in the countryside, etc.) are stronger when they pay attention to how we feed ourselves. Growing, sharing, and preparing food can serve as the entry point for cooperation, allowing us to experiment with community-wide participation in food systems.

An ongoing dance of creativity and appropriation exists between grass-roots inventiveness and corporate and government co-optation. If this dance can be made generative rather than deadly, it can open pathways for transition to new ways of seeing, experiencing, and getting food. Many people are discovering what is needed and inventing livelihoods to meet them. Many fail or become reforms of the dominant system, but together there is promise to transform it. The food sovereignty movement and practitioners of agroecology can navigate this dance by focusing on land use, democracy, cultural vitality, and health, as it seeks to re-centre society on sustainable food and farming. We propose that actions and words be guided by a reconnection of rural and urban, of food and farming, and of agriculture and conservation of other species (Perfecto et al. 2009); that is, of humans with the rest of nature. Food sovereignty aspires to the autonomy of places and networked relations among places, so that biocultural regions - both in long occupied places and in diasporic ones - can evolve democratically from farm and urban garden to the biosphere.

It is useful to remember that most of the farmers of the world can be considered 'indigenous' to the places where they grow food, with an inherited or acquired respect for nature, and for themselves as part of nature. This connotation can become romantic or nostalgic, but it can also be a way to appreciate how much of nature and culture has been deeply compromised by industrial agriculture, which after all is only a few decades old, and how much restoration of balance requires a new way of seeing, experiencing, and getting food. We can see the sophisticated practices of abandoned civilisations, for instance, in the Amazon, where archaeologists have discovered that what was once assumed to be 'natural' fertility was created by farmers with terra preta or dark soil, and where it was supposed only foraging existed (Fraser and Clement 2008). Indigenous cosmologies have entered into popular thought and even laws in parts of Latin America as the idea of buen vivir. We would do well to consider the advice by Gudynas (2011) to seize the opportunity of buen vivir to imagine how to live well with each other and the earth. 


\section{Notes}

* Funding for this IDS Bulletin was provided by IPES-Food in furtherance of their aim to apply a political economy approach in understanding and reforming food systems.

+ This IDS Bulletin represents a collaboration between IDS and IPES-Food. Both organisations are committed to holistic, sustainable, democratic approaches to improving food systems, and to applying excellent research and political economy approaches in working towards these goals. We hope this IDS Bulletin represents the breadth of debate at the 2018 workshop we co-sponsored, on 'Political Economies of Sustainable Food Systems: Critical Approaches, Agendas and Challenges', and that it contributes to the sharing of knowledge in the name of sustainable and equitable food systems.

1 Steve Gliessman, Professor Emeritus of Agroecology, University of California at Santa Cruz, USA.

2 Harriet Friedmann, Professor Emerita of Sociology, Munk School of Global Affairs, University of Toronto, Canada.

3 Philip H. Howard, Associate Professor in the Dept. of Community Sustainability, Michigan State University, USA.

4 https://en.wikipedia.org/wiki/Ny\%C3\%A9l\%C3\% $\%$ A9ni.

\section{References}

Adams, W. and Brock, J.W. (2004) The Bigness Complex: Industry, Labor, and Government in the American Economy, 2nd ed., Redwood City CA: Stanford University Press

Barnes, P. (2014) 'Reskilling as Mastery of Appropriate Technology', Transition US, 7 October, http://transitionus.org/blog/reskillingmastery-appropriate-technology (accessed 9 April 2019)

Bichler, S. and Nitzan, J. (2017) Growing through Sabotage: Energizing Hierarchical Power, Working Papers on Capital as Power 2017/02, Bristol: Capital as Power

Bichler, S. and Nitzan, J. (2012) 'The Asymptotes of Power', Real-World Economics Review 60: 18-53

Blesh, J. and Wolf, S.A. (2014) 'Transitions to Agroecological Farming Systems in the Mississippi River Basin: Toward an Integrated Socioecological Analysis', Agriculture and Human Values 31.4: 621-35, doi:10.1007/s10460-014-9517 (accessed 3 June 2019)

Carolan, M. (2018) The Real Cost of Cheap Food, 2nd ed., London: Routledge

Chappell, M.J. (2017) Beginning to End Hunger: Food and the Environment in Belo Horizonte, Brazil, and Beyond, Oakland CA: University of California Press

Civil Society Mechanism (2016) Connecting Smallholders to Markets: An Analytical Guide, Florence: Terra Nuova, www.csm4cfs.org/connecting-smallholders-markets-analytical-guide/ (accessed 9 April 2019)

Crews, T.E. et al. (2016) 'Going Where No Grains Have Gone Before: From Early to Mid-Succession', Agriculture, Ecosystems and Environment 223: $223-38$ 
Cronon, W. (1991) Nature's Metropolis: Chicago and the Great West, New York NY: W.W. Norton

DeLind, L.B. and Howard, P.H. (2008) 'Safe at Any Scale? Food Scares, Food Regulation, and Scaled Alternatives', Agriculture and Human Values 25.3: 301-17, doi:10.1007/s10460-007-9112-y (accessed 3 June 2019)

De Schutter, O. (2009) 'Guidance in a Time of Crisis: IAASTD and the Human Right to Food. Message from the UN Special Rapporteur on the Right to Food', Enabling Policies for Development and Sustainability from the IAASTD, Side-event to the UN CSD Intergovernmental Preparatory Meeting, New York, 25 February, www.srfood.org/ images/stories/pdf/otherdocuments/18-iaastd-rtf-25-2-2009.pdf (accessed 16 April 2017)

De Schutter, O.; Fishman, C.; Francis, K. and Jamlang, G. (2015) 'Survival by Design', Foreign Policy 213 (July-August): 67-75

Domhoff, G.W. (2014) Who Rules America? The Triumph of the Corporate Rich, 7th ed., New York NY: McGraw-Hill Higher Education

FAO (2018) Scaling up Agroecology Initiative: Transforming Food and Agricultural Systems in Support of the SDGs, Rome: Food and Agriculture Organization of the United Nations

Fraser, J.A. and Clement, C.R. (2008) 'Dark Earths and Manioc Cultivation in Central Amazonia: A Window on Pre-Columbian Agricultural Systems?', ['Terras Pretas e o cultivo de mandioca na Amazônia Central: uma janela para os sistemas agrícolas pré-colombianos?'], Boletim do Museu Paraense Emílio Goeldi, Ciências Humanas 3.2: 175-94, http://dx.doi.org/10.1590/S198181222008000200004 (accessed 9 April 2019)

Freudenburg, W.R. and Alario, M. (2007) 'Weapons of Mass Distraction: Magicianship, Misdirection, and the Dark Side of Legitimation', Sociological Forum 22.2: 146-73, doi:10.1111/j.1573-7861.2007.00011.x (accessed 3 June 2019)

Friedmann, H. (2017) 'Paradox of Transition: Two Reports on How to Move Towards Sustainable Food Systems', Development and Change 48.5: 1210-26, doi:10.1111/dech.12329 (accessed 3 June 2019)

Friedmann, H. (2016) 'Food Regime Analysis and Agrarian Questions: Widening the Conversation', Fournal of Peasant Studies 43.3: 671-92, http://dx.doi.org/10.1080/03066150.2016.1146254 (accessed 9 April 2019)

Friedmann, H. (2011) 'Food Sovereignty in the Urbanized Golden Horseshoe Region of Ontario', in H. Wittman, A.A. Desmarais and N. Wiebe (eds), Food Sovereignty in Canada: Creating fust and Sustainable Food Systems, Winnipeg MB: Fernwood Publishing

Friedmann, H. (2005) 'From Colonialism to Green Capitalism: Social Movements and Emergence of Food Regimes', in F.H. Buttel and P. McMichael (eds), New Directions in the Sociology of Global Development (Research in Rural Sociology and Development, Volume 11), Amsterdam: Elsevier

Gibson-Graham, J.K. (2006) The End of Capitalism (As We Knew It): A Feminist Critique of Political Economy, Minneapolis MN: University of Minnesota Press 
Gliessman, S.R. (2016a) 'Agroecology: Roots of Resistance to Industrialized Food Systems', in V.E. Méndez, C.M. Bacon, R. Cohen and S.R. Gliessman (eds), Agroecology as a Transdisciplinary, Participatory, and Action-Oriented Approach, Advances in Agreocology, Boca Raton FL: CRC Press/Taylor and Francis Group

Gliessman, S.R. (2016b) 'Transforming Food Systems with Agroecology', Agroecology and Sustainable Food Systems 40.3: 187-89, https://doi.org/10.1080/21683565.2015.1130765 (accessed 9 April 2019)

Gliessman, S.R. (2015) Agroecology: The Ecology of Sustainable Food Systems, 3rd ed., Boca Raton FL: CRC Press/Taylor and Francis Group

Gliessman, S.R. (2007) Agroecology: The Ecology of Sustainable Food Systems, 2nd ed., Boca Raton FL: CRC Press/Taylor and Francis Group

Gliessman, S.R. (1997) Agroecology: Ecological Processes in Sustainable Agriculture, Chelsea MI: Ann Arbor Press

GRAIN (2015) 'UPOV 91 and Other Seed Laws: A Basic Primer on How Companies Intend to Control and Monopolise Seeds', 16 October, www.grain.org/e/5314 (accessed 9 April 2019)

GRAIN (2011) 'Food Safety for Whom? Corporate Wealth Versus People's Health', 11 May, www.grain.org/e/4230 (accessed 9 April 2019)

Gramsci, A. (1971) Selections from the Prison Notebooks of Antonio Gramsci, New York NY: International Publishers

Gudynas, E. (2011) 'Buen Vivir: Today's Tomorrow', Development 54.4: 441-47, https://doi.org/10.1057/dev.2011.86 (accessed 9 April 2019)

Ho, P. and Spoor, M. (2006) 'Whose Land? The Political Economy of Land Titling in Transition Economies', Land Use Policy 23:4: 580-87

Hoey, L. and Sponseller, A. (2018) “'It's Hard to Be Strategic When Your Hair Is On Fire": Alternative Food Movement Leaders' Motivation and Capacity to Act', Agriculture and Human Values 35.3: 595-609

Holt-Giménez, E. and Altieri, M.A. (2016) 'Agroecology "Lite": Cooptation and Resistance in the Global North', Food First 38.141: 1-3

Hornborg, A. (2011) Global Ecology and Unequal Exchange: Fetishism in a Zero-Sum World, Abingdon: Routledge

Howard, P.H. (2016) Concentration and Power in the Food System: Who Controls What We Eat? New York NY: Bloomsbury Academic

Howard, P.H. (2015) 'Intellectual Property and Consolidation in the Seed Industry', Crop Science 55.6: 2489-95, doi:10.2135/cropsci2014.09.0669 (accessed 3 June 2019)

IAASTD (2009) Agriculture at a Crossroads, Washington DC: Island Press, http://wedocs.unep.org/handle/20.500.11822/7862 (accessed 3 November 2018)

ILC LEMU (2018) Protecting Customary Tenure Through Principles, Practices, Rights and Responsibilities (PPRR) Books, International Land Coalition Land and Equity Movement of Uganda, www.landcoalition.org/ sites/default/files/documents/resources/ilc-en-gp-uganda.pdf (accessed 22 December 2018)

International Forum for Agroecology (2015) 'Declaration of the International Forum for Agroecology', Nyéléni, Mali, 
www.foodsovereignty.org/wp-content/uploads/2015/02/Downloaddeclaration-Agroecology-Nyeleni-2015.pdf (accessed 9 April 2019)

IPES-Food (2018) Breaking Away from Industrial Food and Farming Systems: Seven Case Studies of Agroecological Transition, Brussels: International Panel of Experts on Sustainable Food Systems

IPES-Food and Frison, E. (2016) From Uniformity to Diversity: A Paradigm Shift from Industrial Agriculture to Diversified Agroecological Systems, Brussels: International Panel of Experts on Sustainable Food Systems Jaffe, J. and Gertler, M. (2006) 'Victual Vicissitudes: Consumer Deskilling and the (Gendered) Transformation of Food Systems', Agriculture and Human Values 23.2: 143-62, doi:10.1007/s10460-005-6098-1 (accessed 3 June 2019)

Jaffee, D. and Howard, P.H. (2016) 'Who's the Fairest of Them All? The Fractured Landscape of US Fair Trade Certification', Agriculture and Human Values 33.4: 813-26, doi:10.1007/s10460-015-9663-2 (accessed 3 June 2019)

Jaffee, D. and Howard, P.H. (2010) 'Corporate Cooptation of Organic and Fair Trade Standards', Agriculture and Human Values 27.4: 387-99, doi:10.1007/s10460-009-9231-8 (accessed 3 June 2019)

Lynn, B.C. (2009) Cornered: The New Monopoly Capitalism and the Economics of Destruction, Hoboken NJ: John Wiley

McKeon, N. (2015) Food Security Governance: Empowering Communities, Regulating Corporations, Abingdon: Routledge

Meyer, D. (2018) 'Trump's Bailout of US Farmers Hit by His Trade War with China? It May End Up Aiding a Giant Chinese Company', Fortune, 26 October, http://fortune.com/2018/10/26/trump-tradewar-china-farmer-aid-smithfield-pork/ (accessed 9 April 2019)

Morgan, K. and Morley, A. (2014) 'The Public Plate: Harnessing the Power of Purchase', in T. Marsden and A. Morley (eds), Sustainable Food Systems: Building a New Paradigm, Abingdon: Routledge

Nitzan, J. (1998) 'Differential Accumulation: Towards a New Political Economy of Capital', Review of International Political Economy 5.2: 169-216, doi:10.1080/096922998347543 (accessed 3 June 2019)

Nitzan, J. and Bichler, S. (2009) Capital as Power: A Study of Order and Creorder, Abingdon: Routledge

Nyéléni (2007) 'Declaration of Nyéléni', Declaration of the Forum for Food Sovereignty, https://nyeleni.org/spip.php?article290 (accessed 5 October 2018)

Oliveira, G. and Hecht, S. (2016) 'Sacred Groves, Sacrifice Zones and Soy Production: Globalization, Intensification and Neo-Nature in South America', Fournal of Peasant Studies 43.2: 251-85, doi:10.1080/03066150.2016.1146705 (accessed 3 June 2019)

Perfecto, I.; Vandermeer, J. and Wright, A.L. (2009) Nature's Matrix: Linking Agriculture, Conservation and Food Sovereignty, London: Earthscan

Prindex (2018) Comparative Report [on perceived security of tenure in 15 countries from sub-Saharan Africa, Latin America, and Southeast Asia], London: Prindex, www.prindex.net/reports/prindexcomparative-report-october-2018/ (accessed 6 November 2018) 
Rosset, P.M. and Altieri, M.A. (1997) 'Agroecology Versus Input Substitution: A Fundamental Contradiction of Sustainable Agriculture', Society and Natural Resources 10.3: 283-95, doi:10.1080/08941929709381027 (accessed 3 June 2019)

Samberg, L.H.; Gerber, J.S.; Ramankutty, N.; Herrero, M. and West, P.C. (2016) 'Subnational Distribution of Average Farm Size and Smallholder Contributions to Global Food Production', Environmental Research Letters 11.12: 124010

Stahlbrand, L. (2016) 'The Food For Life Catering Mark: Implementing the Sustainability Transition in University Food Procurement', Agriculture 6.3: 46, doi:10.3390/agriculture6030046 (accessed 3 June 2019)

Streeck, W. (2017) Buying Time: The Delayed Crisis of Democratic Capitalism, London: Verso

Veblen, T. (1923) Absentee Ownership and Business Enterprise in Recent Times: The Case of America, New York NY: B.W. Huebsch

Walljasper, J. (2011) 'Eight Principles for Managing a Commons', On the Commons, 2 October, www.onthecommons.org/magazine/elinorostroms-8-principles-managing-commmons\#sthash.USCnoDQP.dpbs (accessed 6 November 2018)

Wrong, D.H. (1995) Power: Its Forms, Bases, and Uses, New Brunswick NJ: Transaction Publishers 
This page is intentionally left blank 